\title{
The Relationships Between Vitamin K and Cognition: A Review of Current Evidence
}

\author{
Ludovico Alisi ${ }^{1}$, Roberta Cao ${ }^{2}$, Cristina De Angelis ${ }^{3}$, Arturo Cafolla ${ }^{4}$, Francesca Caramia ${ }^{5}$, \\ Gaia Cartocci ${ }^{5}$, Aloisa Librando ${ }^{1}$ and Marco Fiorelli ${ }^{*}$
}

${ }^{1}$ Department of Sense Organs, Sapienza University of Rome, Rome, Italy, ${ }^{2}$ Department of Radiology, IRCCS San Raffaele Scientific Institute, Milan, Italy, ${ }^{3}$ Department of Radiological, Oncological and Anatomo-Pathological Sciences, Sapienza University of Rome, Rome, Italy, ${ }^{4}$ Department of Cell Biotechnology and Hematology, Sapienza University of Rome, Rome, Italy, ${ }^{5}$ Department of Human Neuroscience, Sapienza University of Rome, Rome, Italy

\section{OPEN ACCESS}

Edited by:

Matilde Inglese,

Icahn School of Medicine at Mount

Sinai, United States

Reviewed by:

Marta Maschio,

Istituto Nazionale del Cancro Regina

Elena, Italy

Maria Maddalena Filippi,

Fatebenefratelli Foundation for Health

Research and Education, Italy

*Correspondence: Marco Fiorelli marco.fiorelli@uniroma1.it

Specialty section: This article was submitted to Multiple Sclerosis and Neuroimmunology,

a section of the journal Frontiers in Neurology

Received: 30 July 2018 Accepted: 22 February 2019 Published: 19 March 2019

Citation:

Alisi L, Cao R, De Angelis C, Cafolla A

Caramia F, Cartocci G, Librando A and Fiorelli $M$ (2019) The

Relationships Between Vitamin $\mathrm{K}$ and Cognition: A Review of Current Evidence. Front. Neurol. 10:239. doi: 10.3389/fneur.2019.00239
Vitamin $\mathrm{K}$ is a fat-soluble nutrient discovered in 1935 and its role in blood coagulation has been thoroughly explored. In recent years, studies conducted in vitro and on animals highlighted vitamin $\mathrm{K}$ involvement in brain cells development and survival. In particular, vitamin $\mathrm{K}$ seems to have an antiapoptotic and anti-inflammatory effect mediated by the activation of Growth Arrest Specific Gene 6 and Protein S. Moreover, this vitamin is involved in sphingolipids metabolism, a class of lipids that participate in the proliferation, differentiation, and survival of brain cells. An altered expression in sphingolipids profile has been related to neuroinflammation and neurodegeneration. This review stems from a growing interest in the role of vitamin $\mathrm{K}$ in brain functions, especially in cognition, also in view of an expected increase of prevalence of Alzheimer's disease and other forms of dementia. It collects recent researches that show interesting, even though not definitive, evidence of a direct correlation between vitamin $\mathrm{K}$ levels and cognitive performance. Moreover, vitamin $\mathrm{K}$ antagonists, used worldwide as oral anticoagulants, according to recent studies may have a negative influence on cognitive domains such as visual memory, verbal fluency and brain volume. The aim of this review is to analyze the evidence of clinical studies carried out up to date on the relationship between vitamin $\mathrm{K}$ intake and cognitive performances. The involvement of vitamin $\mathrm{K}$ antagonists (VKAs) in declining cognitive performances is also addressed separately.

Keywords: vitamin K, phylloquinone, cognitive impairment, vitamin K antagonists, warfarin

\section{INTRODUCTION}

Vitamin $\mathrm{K}$ is a fat-soluble nutrient mainly found in green leafy vegetables as phylloquinone (Vitamin K1). This vitamin is widely known for its procoagulant effect. It acts as a cofactor for the enzyme that allows the activation of vitamin K-dependent factors (II, VII, IX, X, protein C, and protein S). A recent review collected studies that show its involvement in the metabolism of the central nervous system (CNS), suggesting the possibility that a vitamin K deficiency might be related to the onset of cognitive impairment (1).

These recently discovered functions, revealed that this vitamer participate in the enzymatic activation of growth-arrest specific 6 protein (Gas-6) and protein S. The first has an anti-apoptotic, mitogenic, and myelinating activity, the latter offers neuronal protection during ischemic/hypoxic injury both in vivo and in vitro (2-4). Furthermore, vitamin $\mathrm{K}$ is known to be an inductor 
of sphingolipids synthesis. These polar lipids are an essential part of CNS cell membrane and are linked to neuronal proliferation and differentiation (1). Several studies are also investigating the correlation between cognitive impairment and the use of vitamin $\mathrm{K}$ antagonists (VKAs, i.e., warfarin, acenocoumarol, and fluindion) as oral anticoagulants. In fact, these Coumarin derivatives prevent the recycle of vitamin $\mathrm{K}$ after the $\mathrm{\gamma}$ carboxylation (5).

Due to the progressive aging of global population, data indicate that cases of dementia will double between 2020 and 2040, rising up to 81 million and consequently burdening society and national health systems. For instance, Alzheimer's disease $(\mathrm{AD})$ cases in the US will rise from 5.4 million up to 13.8 million by mid-century $(6,7)$. Hence the importance of identifying modifiable factors that could impact the course of neurodegenerative pathologies. The aim of this review is to analyze the evidence of clinical studies carried out up to date examining the hypothesis of a cognitive decline among adults with low serum levels or dietary intake of vitamin K. Moreover, studies evaluating the potential link between VKAs and cognitive functions were also included.

\section{DEMENTIA AND COGNITIVE IMPAIRMENT}

Dementia can be defined as a clinical syndrome of mental capacity characterized by a substantial global decline in cognitive function that is not attributable to altered consciousness; it consists of a combination of symptoms attributable to various causes or pathological events (8). Cognitive impairment is a definition used in this review to indicate alterations in multiple cognitive domains highlightable with standardized tests, as clinically manifest dementia is often preceded by a heterogeneous spectrum of cognitive performances (9).

It is difficult to find univocal data about the prevalence of cognitive impairment and other forms of dementia (10); some studies show that the global prevalence of dementia varies among different countries, this could be related to a large number of variables including education, mean age, socioeconomic level, lack of a comparable methodology (11). However, it can certainly be affirmed that the two most common type of dementia in Western countries are Alzheimer's disease (up to $60 \%$ of cases) and vascular dementia (up to $20 \%$ of cases). These two forms of dementia are easily mistaken one for another due to their similarities in symptomatology, pathophysiology, and risk factors (12).

The mechanism underlying Alzheimer's disease is the deposition of $\beta$-amyloid peptide $(\mathrm{A} \beta)$ and the neurofibrillary tangles of the microtubule binding protein tau. In particular, $\mathrm{A} \beta$ peptides are responsible for the massive neuronal death that defines the disease (13).

A few studies concluded that Vitamin $K$ seems to prevent $A \beta$ induced apoptosis through the activation of Gas-6, showing a pro-survival effect on brain cells (14).

Regarding vascular dementia, the main causes are represented by several vascular pathologies that result in cerebral ischemia. Studies published in the last years have attributed to Protein
$\mathrm{S}$ (activated by vitamin $\mathrm{K}$ ) a role in improving post-ischemic cerebral blood flow (15) and potentially leading to a more favorable cognitive outcome.

\section{VITAMIN K STRUCTURE AND FUNCTION}

Vitamin $\mathrm{K}$ can be found as phylloquinone (the main dietary source of vitamin $\mathrm{K}$ ) and it's also identified as menaquinones (vitamin K2) which include several vitamers of bacterial origin (2). Menaquinone-4 (MK-4) is the most represented vitamer in both human and rats' brains $(16,17)$.

MK-4 seems to protect against oxidative damage and inflammatory cascade activation in in vitro studies $(18,19)$. In addition, in murine models MK-4 depletion has been found correlated with worse cognitive performances (20).

Vitamin $\mathrm{K}$ is widely known for its role in blood coagulation as the cofactor of $\mathrm{\gamma}$-glutamyl carboxylase that allows the activation of vitamin K-dependent factors such as factor II, VII, IX, X, protein $\mathrm{C}$, and protein $\mathrm{S}$. Vitamin $\mathrm{K}$ is also involved in the $\mathrm{\gamma}$-carboxylation of two vitamin $\mathrm{K}$-dependent proteins whose activity contributes to an adequate cerebral homeostasis, namely Gas-6 and protein S $(3,4)$. Moreover, vitamin $\mathrm{K}$ participates as a cofactor in the synthesis of sphingolipids, an important constituent of brain cells membrane (21). Several studies conducted on in vitro and murine models have highlighted the role of these constituents in brain metabolism. In some cases, a correlation with neurodegenerative diseases emerged that could be further examined trough human studies.

\section{Gas-6}

Gas-6 has a central role in the development and survival of nervous system. In addition, it shows an anti-apoptotic, mitogenic, and myelinating activity in neuronal and glial cells (1).

Gas- 6 binds and activates the receptor tyrosine kinases of the Tyro3, Axl, and Mer (TAM) family. Axl is involved in the proliferation of numerous cell types and in the survival of gonadotropin-releasing hormone $(\mathrm{GnRH})$ neurons allowing their migration from the olfactory bulb to the hypothalamus $(22,23)$.

Mer protects primary macrophages from oxidative stress induced-apoptosis (24).

The specific role of Tyro3 in cell survival is yet to be defined, but activities similar to Axl have been observed concerning the migration of GnRH neurons A (25-27).

An in vitro study revealed that recombinant Gas-6 protects hippocampal rats' neurons from apoptosis, underlining the prosurvival effect of this protein through the activation of TAM proteins (28).

Through the activation of $\mathrm{Axl}$ and phosphatidylinositol 3-kinase (PI3K) pathways, Gas-6 modulates oligodendrocyte survival and microglial phenotype both in vitro and in vivo (3) preventing tumor necrosis factor alpha-induced apoptosis. A study on cuprizone-induced demyelination model (adopted as a model of multiple sclerosis) revealed that the deletion of Gas-6/Axl signaling leads to prolonged neuroinflammation with axonal damage and consistent demyelination $(29,30)$. This immune-regulatory role links Gas-6 to autoimmune disorders, 
more specifically to the pathogenesis of multiple sclerosis (MS) $(31,32)$.

Studies developed using murine culture of microglial cells showed that Gas-6 downregulates the expression of Interleukin$1 \mathrm{~b}$ e induced nitric oxide synthase, thereby reducing the proinflammatory response (33). Two recent murine models using knock-out mice for Mer and Axl, demonstrated a reduced recruitment of microglial cells to neuronal sites of injury, also affecting the phagocytic activity through cytoskeleton changes $(34,35)$.

Furthermore, Gas-6 has shown a decrease of B-amyloidinduced apoptosis, a hallmark of Alzheimer's disease, through the inhibition of low-voltage $\mathrm{Ca}^{2+}$ influx channels (14). However, a more recent study found that Gas-6 inhibits Tyro3 whose effects prevent $\beta$-amyloid deposition (36).

\section{Protein S}

Historically protein $\mathrm{S}$ has been known for its anticoagulant effect, but recent studies are exploring further effects, such as a possible role in inflammation, angiogenesis, and cancer (37). As well as in ameliorating post-ischemic cerebral blood flow (15).

Protein S shares with Gas-6 almost half of its amino acid structure (44\%) (4), and consequently it performs part of its actions as a TAM receptor ligand. Zhu et al. showed a direct correlation between the inhibition of Tyro3/Akt signaling pathway and the hypoxic-induced apoptosis of hippocampal neurons, underlining a potential protective effect of protein $S$ in cerebral infarct (38). In particular, protein $S$ has a protective effect against NMDA-induced toxicity and apoptosis via the Tyro3/Akt pathway (39). This finding may suggest a possible role of protein $\mathrm{S}$ as an adjunct of tissue Plasminogen Activator to reduce cerebral post-ischemic toxicity (40), without increasing the risk of bleeding when administered alone in high concentration to stroke rodent models (15). An additional property of protein $\mathrm{S}$ seems to be the preservation of the integrity of the bloodbrain barrier (BBB) as it operates as a safeguard against chronic ischemic damage and BBB-related disorders (41).

\section{Sphingolipid Metabolism}

Sphingolipids is one of the major classes of eukaryotic lipids and an essential component of cell membranes and their synthesis is known to be induced by vitamin $\mathrm{K}(21)$.

The sphingolipids most frequently observed in neuronal cell membranes are ceramides, sphingomyelin, cerebrosides, sulfatides, and gangliosides (42). This class of lipids seems to be a vital modulator of cell proliferation, differentiation, and survival (43). A growing amount of evidence are associating sphingolipids metabolism to the pathophysiology of CNS diseases. These polar lipids have been related to a neuroinflammatory and neurodegenerative states due to microglial activation and accumulation of amyloid precursor protein (APP) (44).

These are at the basis of the development of several pathologies like $\mathrm{AD}(43,45)$, where inflammation is a consequence of microglial activation triggered by $\beta$-amyloid plaques (46).

Lastly, sphingolipids guide the process of myelination in the CNS and are themselves major components of oligodendrocyte membrane. In the serum and cerebrospinal fluid of patients affected by multiple sclerosis antibodies have been detected against myelinic sphingolipids $(47,48)$ along with ceramide accumulation in active lesions (49).

\section{The Assessment of Vitamin K Status}

Both biomarkers and questionnaires have been suggested to evaluate vitamin $\mathrm{K}$ status. Circulating phylloquinone can be measured with high performance liquid chromatography (HPLC) a method that responds to changes in dietary phylloquinone intake. Serum phylloquinone should be measured in fasting samples to better reflect overall nutritional status. Moreover, vitamin $\mathrm{K}$ serum levels are influenced by serum triglycerides and should be corrected accordingly. There is currently no established threshold of circulating phylloquinone that indicates insufficiency or deficiency (50).

Other circulating markers are: PIVKA-II (protein induced by vitamin $\mathrm{K}$ absence-II) that has shown low sensitivity to dietary variation of vitamin $\mathrm{K}$; undercarboxylated fraction of osteocalcin (unOc) and desphospho-uncarboxylated matrix Gla-protein (dpucMGP) that are both more sensitive than PIVKA-II but still conditioned by factors such as age and the total amount of matrix Gla-proteins available (50).

Vitamin $\mathrm{K}$ intake can be assessed with questionnaires such as the food frequency questionnaire (FFQ) or dietary records. While being efficient in terms of costs and time and easy to implement, questionnaires rely on the recall ability and perceptions of individuals' diet and therefore may be subjected to bias (51).

Considering the lack of a single gold standard measure, and the limitations affecting the available methods, vitamin $\mathrm{K}$ status may be best assessed with a combination of both questionnaires and biomarkers (50).

\section{VKAS-BRAIN RELATIONSHIP}

VKAs exercise their function by blocking the activity of vitamin $\mathrm{K}$ oxidoreductase (VKOR) preventing the recycle of vitamin K after the $\mathrm{y}$-carboxylation (5). The possibility of an adverse impact of VKAs on the brain has been evident since the finding of abnormalities of the CNS in newborns exposed to warfarin or other coumarin derivatives (52). However, detailed mechanisms are yet to be comprehended. Studies on whether Gas- 6 and protein $S \mathrm{\gamma}$-carboxylation are impaired by VKAs in the human brain have not yet been conducted. Studies performed on murine models have shown how VKAs determine a decrease in MK4 brain concentrations, the most represented vitamer in rats' brain (16). Nagakawa et al. identificated the enzyme responsible for the conversion of phylloquinone in MK-4 (UBIAD1) (17) and Tamadon-Nejad et al. demonstrated that despite an excess of phylloquinone in rats' brain, MK-4 brain concentrations remained low in warfarin treated rats suggesting an alteration of the MK- 4 biosynthetic pathway in the presence of warfarin (53). Moreover, rats treated with VKAs showed worse performances in tests to evaluate their cognitive and behavioral functions $(53,54)$.

It is well known how anticoagulant use can decrease the risk of dementia by reducing the number of cerebral ischemic events in AF patients (55). 
Mostaza et al. observed that in a population taking vitamin $\mathrm{K}$ antagonists, there was a trend toward higher warfarin prescription among patients with cognitive impairment, regardless dependency or frailty. Thus, a thorough evaluation on the association between non-vitamin $\mathrm{K}$ antagonists oral anticoagulants (NOACs) use and cognitive decline is crucial (56).

A recent meta-analysis found a borderline significant association between the use of NOACs and the lower risk of cognitive impairment when compared with VKAs and acetylsalicylic acid (57).

Similar findings were observed in other studies where NOAC were considered an optimal or even better alternative to warfarin, due to their lower bleeding risk and variability in anticoagulation effect (58). A previous study validated the same hypothesis: NOACs provide a better protection against atrial fibrillationrelated stroke in terms of lower risk of cerebral ischemic events and new-onset dementia than those treated with warfarin (59).

\section{VITAMIN K AND COGNITIVE DECLINE}

Considering the numerous roles of Vitamin $\mathrm{K}$ highlighted in the previous studies, in recent years some authors have started to investigate the potential link between cognitive impairment and vitamin $\mathrm{K}$.

Whether vitamin $\mathrm{K}$ deficiency is associated to cognitive decline is still a matter of debate today. From the literature search, we were able to include 7 human studies and all, except one (60), confirmed an association between vitamin $\mathrm{K}$ and cognitive function among older adults (Table 1).

Six studies demonstrated, in a population of 65 years and older, a direct correlation between low vitamin $\mathrm{K}$ dietary intake or serum concentration and deteriorated cognitive and behavioral performances. In particular, Presse et al. in 2013 published the results of a cross sectional study conducted on 320 elderly, aged 70-85, free of cognitive impairment from the NuAge study cohort (63). Phylloquinone serum concentration analysis was measured using High performance liquid chromatography (HPLC), a method already validated as an indicator of dietary phylloquinone intake over a long period of time. Circulating phylloquinone concentrations are conditioned by the blood lipid profile that needs to be assessed as well while using HPLC (67). Cognitive assessment was performed using specific tests for each cognitive domain (verbal and non-verbal episodic memory, executive functions, and speed of processing). Results showed that recruited subjects with higher serum phylloquinone performed better in verbal episodic memory, while no correlation was found with non-verbal episodic memory, executive functions, and speed of processing, underlining the role of vitamin $\mathrm{K}$ in memory consolidation (63). These results are supported by a previous murine model where rodents underwent a 5-days learning test in the Morris Water Maze and those fed with lower vitamin $\mathrm{K}$ levels required longer time to perform the task compared to those adequately fed (20).

Two studies evaluated vitamin $\mathrm{K}$ intake using a semi quantitative food frequency questionnaire (FFQ). They observed a less severe subjective memory complaint (65) as well as a better cognition and less behavioral disturbances (64) among geriatric patients with higher vitamin $\mathrm{K}$ intake. The FFQ is a 50 items questionnaire that aims to evaluate vitamin $\mathrm{K}$ dietary intake. Although it has been validated in elderly people (68) it may result in an underestimation when investigating patients with cognitive decline. Therefore, the FFQ may not be as representative of phylloquinone intake as its serum levels measured with HPLC in this specific circumstance.

In line with previous studies, Kiely et al. described that elderly with poor cognitive functions, evaluated with MMSE, had the lowest dietary vitamin $\mathrm{K}$ intake (assessed with FFQ). Similar results were observed correlating MMSE scores and phylloquinone serum levels measured with HPLC (66).

Further publications highlighted the potential role of this vitamer among patients with Alzheimer's disease-related dementia $(61,62)$, who were found with significant lower levels of vitamin $\mathrm{K}$ even after data were adjusted for energy intakes. In particular, Presse et al. reported in 2008 how vitamin K intake, evaluated with 3-5 days diet records, were notably lower in patients with early stages of AD. Partially limiting the strength of this study are the diet records used, as they show limited value for the assessment of vitamin $\mathrm{K}$ intake (62).

Opposite results were obtained by Van Den Heuvel et al. (60) in a middle-age sample (55-65 years) of 599 individuals, measuring vitamin $\mathrm{K}$ in an indirect way through levels of desphospho-uncarboxylated matrix Gla-protein (dp-ucMGP). Over the 6 years follow up, no significant association between vitamin $\mathrm{K}$ and cognitive decline was found. The recruitment criterion of a different age group may be the reason why contrasting results were observed, since the brain might be susceptible to nutrient deficiency in different ways at different times in life (20). Moreover, as stated by the authors themselves, dp-ucMGP may not be the most suitable marker of vitamin $\mathrm{K}$ levels in the brain (60).

An emerging issue is how the use of VKAs could influence brain metabolism and this topic is analyzed separately. The few papers published until now point out, to a limited extent, a potential correlation between the use of VKAs and both cognitive decline and brain focal atrophies (Table 2).

Ferland et al. observed in a large cohort study a significant decrease in visual memory and verbal fluency among patients treated with VKAs when compared to individuals under no blood-thinning treatment, but no association was observed between the global cognitive function and VKAs use over at 10 years follow up (70).

Brangier et al. analyzed the brain volume, using 3 or 1.5 Tesla MRI, of 54 subjects (18 under VKAs treatment and 36 matched controls) and found a significant inverse correlation between the duration of drug exposure and gray/white matter volume in the right frontal inferior operculum, right precuneus, and left middle frontal gyrus (71). The same author found an important decline in executive functions (assessed with frontal assessment battery) among geriatric patients treated with VKAs over at 24 months follow up. It's worth noticing how, in the same study, decline in Mini mental state examination (MMSE) scores, used as an assessment of cognitive performance, was not found significantly associated with VKAs use over the same period of time (72). 


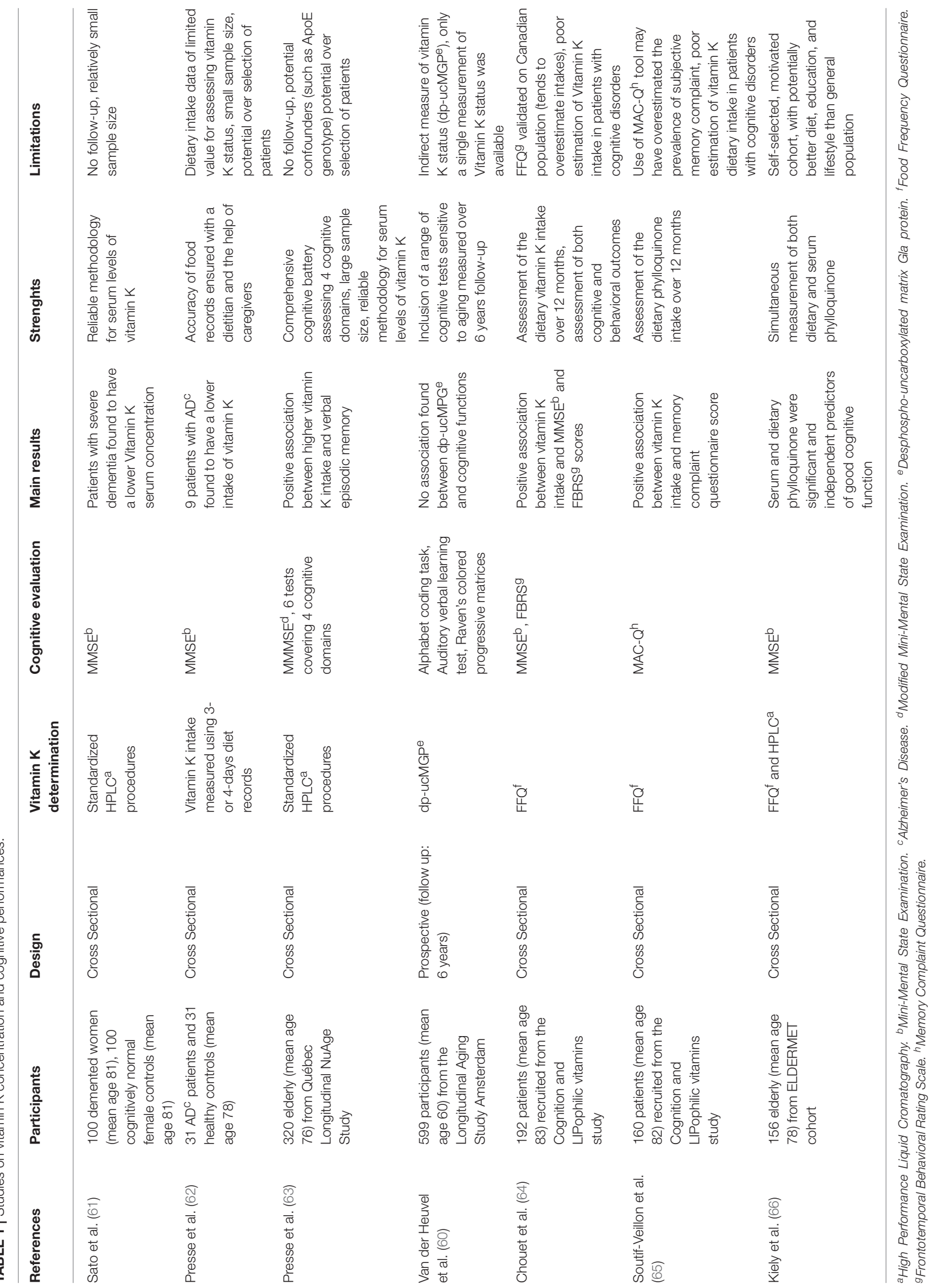




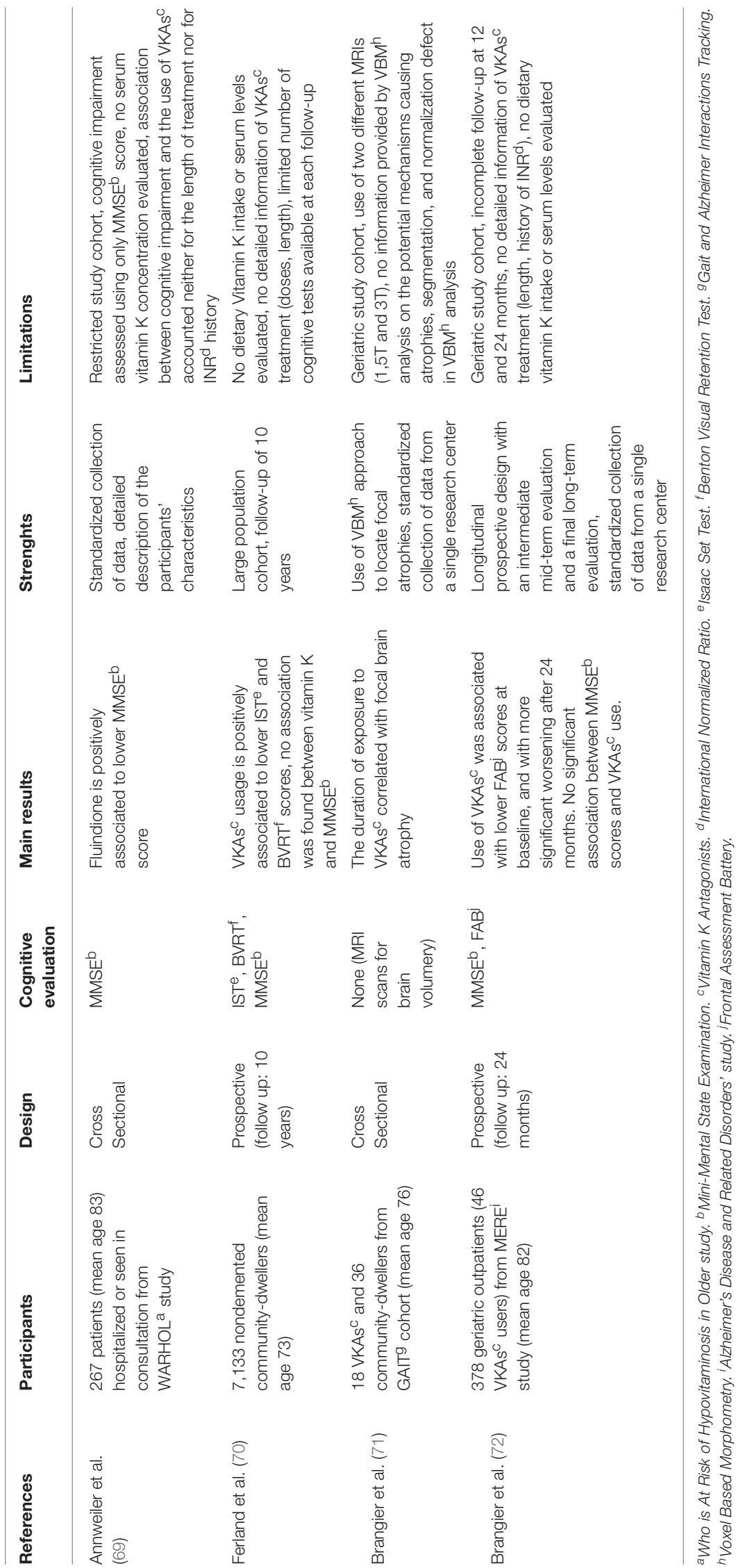


Lastly, Annweiler et al. in 2015 reported a 15\% higher risk of cognitive impairment in patients treated with fluindione which is used as an anticoagulant drug. The positive association (not observed in patients treated with warfarin or acenocoumarol) remained statistically significant even after adjustment for covariables (69).

Clinical studies have suggested that VKAs use does not affect vitamin $\mathrm{K}$ plasma concentration (73) and involved molecular patterns that might lead to cognitive impairment in humans using VKAs are yet to be comprehended.

When implying an involvement of VKAs in cognitive impairment it must be considered that patients are under treatment for pathologies like atrial fibrillation, that can possibly influence, to some level, mental deterioration (74).

\section{CONCLUSIONS}

The present review stems from a growing interest in the role of vitamin $\mathrm{K}$ in brain function, especially in cognition. It collected recent contributions to the topic, showing interesting, even though not definitive, evidence of direct correlation between vitamin $\mathrm{K}$ levels and cognitive performance. Moreover, VKAs might influence negatively some cognitive domains such as visual memory and verbal fluency and the brain volume. Only a small number of publications were based on studies performed on humans, limiting the amount of papers included. These studies were heterogeneous in several ways: study design, markers used to measure vitamin $\mathrm{K}$ levels, method used to assess

\section{REFERENCES}

1. Ferland G. Vitamin K, an emerging nutrient in brain function. BioFactors. (2012) 38:151-7. doi: 10.1002/biof.1004

2. Ferland G. Vitamin K and brain function. Semin Thromb Hemost. (2013) 39:849-55. doi: 10.1055/s-0033-1357481

3. Binder MD, Kilpatrick TJ. TAM receptor signalling and demyelination. Neurosignals. (2009) 17:277-87. doi: 10.1159/000231894

4. Manfioletti G, Brancolini C, Avanzi G, Schneider C. The protein encoded by a growth arrest-specific gene (gas6) is a new member of the vitamin K-dependent proteins related to protein S, a negative coregulator in the blood coagulation cascade. Mol Cell Biol. (1993) 13:4976-85. doi: 10.1128/MCB.13.8.4976

5. Van Gorp RH, Schurgers LJ. New insights into the pros and cons of the clinical use of vitamin $\mathrm{K}$ antagonists (VKAs) versus direct oral anticoagulants (DOACs). Nutrients. (2015) 7:9538-57. doi: 10.3390/nu7115479

6. Alzheimer's Association. 2016 Alzheimer's disease facts and figures. Alzheimers Dement J Alzheimers Assoc. (2016) 12:459-509.57. doi: 10.1016/j.jalz.2016.03.001

7. Ferri CP, Prince M, Brayne C, Brodaty H, Fratiglioni L, Ganguli M, et al. Global prevalence of dementia: a Delphi consensus study. Lancet. (2005) 366:2112-7. doi: 10.1016/S0140-6736(05)67889-0

8. Palm R, Jünger S, Reuther S, Schwab CG, Dichter MN, Holle B, et al. People with dementia in nursing home research: a methodological review of the definition and identification of the study population. BMC Geriatr. (2016) 5:16. doi: 10.1186/s12877-016-0249-7

9. Lopez OL. Mild cognitive impairment. Continuum. (2013) 19:411-24. doi: 10.1212/01.CON.0000429175.29601.97

10. Rizzi L, Rosset I, Roriz-Cruz M. Global epidemiology of dementia: alzheimer's and vascular types. BioMed Res Int. (2014) 2014:908915. doi: 10.1155/2014/908915 cognitive performance and age of patients included in the studies. Further evidence should be gathered using more standardized methodology to foster comparability of results.

The paucity of published papers suggests the need of a more thorough investigation from the scientific community, using randomized trials with large samples to confirm the hypothesis that low vitamin $\mathrm{K}$ can be associated to cognitive decline. A standardized methodology for both cognitive evaluation and vitamin $\mathrm{K}$ dietary intake and serum concentrations must be adopted in order to develop more comparable and reliable data.

Due to the large number of individuals treated with VKAs, a large prospective study is possible and could be crucial to elucidate the influence of these drugs on vitamin $\mathrm{K}$ serum levels and consequently on cognitive decline.

In conclusion, considering the growing social and economic burden linked to the increasing number of patients suffering from cognitive impairment and dementia, further researches on this topic can prove to be beneficial and applicable results can be expected.

\section{AUTHOR CONTRIBUTIONS}

MF and LA conceived the original idea. LA, CD, and RC organized the database and wrote the various sections of this review. AC, MF, FC, AL, and GC supervised and made sure that this work was accurate and formally correct. All authors reviewed the manuscript before the submission.

11. Suh GH, Shah A. A review of the epidemiological transition in dementiacross-national comparisons of the indices related to Alzheimer's disease and vascular dementia. Acta Psychiatr Scand. (2001) 104:4-11. doi: 10.1034/j.1600-0447.2001.00210.x

12. Kalaria RN, Maestre GE, Arizaga R, Friedland RP, Galasko D, Hall K, et al. Alzheimer's disease and vascular dementia in developing countries: prevalence, management, and risk factors. Lancet Neurol. (2008) 7:812-26. doi: 10.1016/S1474-4422(08)70169-8

13. Murphy MP, LeVine H. Alzheimer's disease and the $\beta$-amyloid peptide. $J$ Alzheimers Dis JAD. (2010) 19:311. doi: 10.3233/JAD-2010-1221

14. Yagami T, Ueda K, Asakura K, Sakaeda T, Nakazato H, Kuroda T, et al. Gas6 rescues cortical neurons from amyloid beta protein-induced apoptosis. Neuropharmacology. (2002) 43:1289-96. doi: 10.1016/S0028-3908(02)00333-7

15. Liu D, Guo H, Griffin JH, Fernández JA, Zlokovic BV. Protein S confers neuronal protection during ischemic/hypoxic injury in mice. Circulation. (2003) 107:1791-6. doi: 10.1161/01.CIR.0000058460.34453.5A

16. Ferland G, Doucet I, Mainville D. Phylloquinone and menaquinone-4 tissue distribution at different life stages in male and female spraguedawley rats fed different VK levels since weaning or subjected to a $40 \%$ calorie restriction since adulthood. Nutrients. (2016) 8:141. doi: 10.3390/nu 8030141

17. Nakagawa K, Hirota Y, Sawada N, Yuge N, Watanabe M, Uchino Y, et al. Identification of UBIAD1 as a novel human menaquinone-4 biosynthetic enzyme. Nature. (2010) 468:117-21. doi: 10.1038/nature09464

18. Ohsaki Y, Shirakawa H, Hiwatashi K, Furukawa Y, Mizutani T, Komai M. Vitamin K suppresses lipopolysaccharide-induced inflammation in the rat. Biosci Biotechnol Biochem. (2006) 70:926-32. doi: 10.1271/bbb.70.926

19. Ohsaki Y, Shirakawa H, Miura A, Giriwono PE, Sato S, Ohashi A, et al. Vitamin K suppresses the lipopolysaccharide-induced expression of inflammatory cytokines in cultured macrophage-like cells via the inhibition of the activation of nuclear factor $\kappa \mathrm{B}$ through the repression 
of IKK $\alpha / \beta$ phosphorylation. J Nutr Biochem. (2010) 21:1120-6. doi: 10.1016/j.jnutbio.2009.09.011

20. Carrié I, Bélanger E, Portoukalian J, Rochford J, Ferland G. Lifelong lowphylloquinone intake is associated with cognitive impairments in old rats. $J$ Nutr. (2011) 141:1495-501. doi: 10.3945/jn.110.137638

21. Lev M, Milford AF. The 3-ketodihydrosphingosine synthetase of Bacteroides melaninogenicus: induction by vitamin K. Arch Biochem Biophys. (1973) 157:500-8. doi: 10.1016/0003-9861(73)90668-1

22. Linger RM, Keating AK, Earp HS, Graham DK. TAM receptor tyrosine kinases: biologic functions, signaling, and potential therapeutic targeting in human cancer. Adv Cancer Res. (2008) 100:35-83. doi: 10.1016/S0065-230X(08)00002-X

23. Allen MP, Zeng C, Schneider K, Xiong X, Meintzer MK, Bellosta P, et al. Growth arrest-specific gene 6 (Gas6)/adhesion related kinase (Ark) signaling promotes gonadotropin-releasing hormone neuronal survival via extracellular signal-regulated kinase (ERK) and Akt. Mol Endocrinol. (1999) 13:191-201. doi: 10.1210/mend.13.2.0230

24. Anwar A, Keating AK, Joung D, Sather S, Kim GK, Sawczyn KK, et al. Mer tyrosine kinase (MerTK) promotes macrophage survival following exposure to oxidative stress. J Leukoc Biol. (2009) 86:73-9. doi: 10.1189/JLB.0608334

25. Pierce A, Bliesner B, Xu M, Nielsen-Preiss S, Lemke G, Tobet S, et al. Axl and Tyro3 modulate female reproduction by influencing gonadotropin-releasing hormone neuron survival and migration. Axl and Tyro3 modulate female reproduction by influencing gonadotropin-releasing hormone neuron survival and migration. Mol Endocrinol. (2008) 22:2481-95. doi: 10.1210/me.2008-0169

26. Pierce AM, Keating AK. TAM receptor tyrosine kinases: expression, disease and oncogenesis in the central nervous system. Brain Res. (2014) 1542:206-20. doi: 10.1016/j.brainres.2013.10.049

27. Salian-Mehta S, Xu M, Wierman ME. AXL and MET crosstalk to promote gonadotropin releasing hormone $(\mathrm{GnRH})$ neuronal cell migration and survival. Mol Cell Endocrinol. (2013) 374:92-100. doi: 10.1016/j.mce.2013.04.018

28. Funakoshi H, Yonemasu $T$, Nakano $T$, Matumoto $K$, Nakamura $T$. Identification of Gas6, a putative ligand for Sky and Axl receptor tyrosine kinases, as a novel neurotrophic factor for hippocampal neurons. J Neurosci Res. (2002) 68:150-60. doi: 10.1002/jnr.10211

29. Ray AK, DuBois JC, Gruber RC, Guzik HM, Gulinello ME, Perumal G, et al. Loss of Gas6 and Axl signaling results in extensive axonal damage, motor deficits, prolonged neuroinflammation, and less remyelination following cuprizone exposure. Glia. (2017) 65:2051-69. doi: 10.1002/glia.23214

30. Shankar SL, O'Guin K, Kim M, Varnum B, Lemke G, Brosnan $\mathrm{CF}$, et al. Gas6/Axl signaling activates the phosphatidylinositol 3kinase/Akt1 survival pathway to protect oligodendrocytes from tumor necrosis factor alpha-induced apoptosis. J Neurosci. (2006) 26:5638-48. doi: 10.1523/JNEUROSCI.5063-05

31. Bellan M, Pirisi M, Sainaghi T. The Gas6/TAM system and multiple sclerosis. Int J Mol Sci. (2016) 17:1807. doi: 10.3390/ijms17111807

32. Sainaghi PP, Collimedaglia L, Alciato F, Molinari R, Sola D, Ranza E, et al. Growth arrest specific gene 6 protein concentration in cerebrospinal fluid correlates with relapse severity in multiple sclerosis. Mediators Inflamm. (2013) 2013:406483. doi: 10.1155/2013/406483

33. Grommes C, Lee CY, Wilkinson BL, Jiang Q, Koenigsknecht-Talboo JL, Varnum B, et al. Regulation of microglial phagocytosis and inflammatory gene expression by Gas6 acting on the Axl/Mer family of tyrosine kinases. J Neuroimmune Pharmacol. (2008) 3:130-40. doi: 10.1007/s11481-0079090-2

34. Fourgeaud L, Través PG, Tufail Y, Leal-Bailey H, Lew ED, Burrola PG, et al. TAM receptors regulate multiple features of microglial physiology. Nature. (2016) 532:240-4.doi: 10.1038/nature17630

35. Tang Y, Wu S, Liu Q, Xie J, Zhang J, Han D, et al. Mertk deficiency affects macrophage directional migration via disruption of cytoskeletal organization. PLoS ONE. (2015) 10:e0117787. doi: 10.1371/journal.pone.0117787

36. Zheng Y, Wang Q, Xiao B, Lu Q, Wang Y, Wang X. Involvement of receptor tyrosine kinase Tyro3 in amyloidogenic APP processing and $\beta$-amyloid deposition in Alzheimer's disease models. PLoS ONE. (2012) 7:e39035. doi: 10.1371/journal.pone.0039035
37. Suleiman L, Négrier C, Boukerche H. Protein S: a multifunctional anticoagulant vitamin K-dependent protein at the crossroads of coagulation, inflammation, angiogenesis, and cancer. Crit Rev Oncol Hematol. (2013) 88:637-54.doi: 10.1016/j.critrevonc.2013.07.004

38. Zhu YZ, Wang W, Xian N, Wu B. Inhibition of TYRO3/Akt signaling participates in hypoxic injury in hippocampal neurons. Neural Regen Res. (2016) 11:752-7. doi: 10.4103/1673-5374.182701

39. Zhong Z, Wang Y, Guo H, Sagare A, Fernández JA, Bell RD, et al. Protein $S$ protects neurons from excitotoxic injury by activating the TAM receptor Tyro3-phosphatidylinositol 3-kinase-Akt pathway through its sex hormone-binding globulin-like region. J Neurosci. (2010) 30:15521-34. doi: 10.1523/JNEUROSCI.4437-10.2010

40. Guo H, Barrett TM, Zhong Z, Fernández JA, Griffin JH, Freeman RS, et al. Protein S blocks the extrinsic apoptotic cascade in tissue plasminogen activator/N-methyl D-aspartate-treated neurons via Tyro3-Akt-FKHRL1 signaling pathway. Mol Neurodegener. (2011) 6:13. doi: $10.1186 / 1750-1326-6-13$

41. Zhu D, Wang Y, Singh I, Bell RD, Deane R, Zhong Z, et al. Protein $\mathrm{S}$ controls hypoxic/ischemic blood-brain barrier disruption through the TAM receptor Tyro3 and sphingosine 1-phosphate receptor. Blood. (2010) 115:4963-72.doi: 10.1182/blood-2010-01-262386

42. Hannun YA, Obeid LM. Sphingolipids and their metabolism in physiology and disease. Nat Rev Mol Cell Biol. (2018) 19:175-91. doi: $10.1038 / \mathrm{nrm} .2017 .107$

43. Assi E, Cazzato D, De Palma C, Perrotta C, Clementi E, Cervia D. Sphingolipids and brain resident macrophages in neuroinflammation: an emerging aspect of nervous system pathology. Clin Dev Immunol. (2013) 2013:309302. doi: 10.1155/2013/309302

44. Tamboli IY, Hampel H, Tien NT, Tolksdorf K, Breiden B, Mathews PM, et al. Sphingolipid storage affects autophagic metabolism of the amyloid precursor protein and promotes Abeta generation. J Neurosci. (2011) 31:183749. doi: 10.1523/JNEUROSCI.2954-10.2011

45. Puglielli L, Ellis BC, Saunders AJ, Kovacs DM. Ceramide stabilizes $\beta$-site amyloid precursor protein-cleaving enzyme 1 and promotes amyloid $\beta$-peptide biogenesis. J Biol Chem. (2003) 278:19777-83. doi: $10.1074 /$ jbc.M300466200

46. Dheen ST, Kaur C, Ling EA. Microglial activation and its implications in the brain diseases. Curr Med Chem. (2007) 14:1189-97. doi: 10.2174/092986707780597961

47. Menge T, Lalive PH, von Büdingen HC, Cree B, Hauser SL, Genain CP. Antibody responses against galactocerebroside are potential stage-specific biomarkers in multiple sclerosis. J Allergy Clin Immunol. (2005) 116:453-9. doi: 10.1016/j.jaci.2005.03.023

48. Haghighi S, Lekman A, Nilsson S, Blomqvist M, Andersen O. Myelin glycosphingolipid immunoreactivity and CSF levels in multiple sclerosis. Acta Neurol Scand. (2012) 125:64-70. doi: 10.1111/j.1600-0404.2011.01554

49. Kim S, Steelman AJ, Zhang Y, Kinney HC, Li J. Aberrant upregulation of astroglial ceramide potentiates oligodendrocyte injury. Brain Pathol. (2012) 22:41-57. doi: 10.1111/j.1750-3639.2011.00501.x

50. Shea MK, Booth SL. Concepts and controversies in evaluating vitamin K status in population-based studies. Nutrients. (2016) 8:1. doi: 10.3390/nu8010008

51. Westerterp KR, Goris AH. Validity of the assessment of dietary intake: problems of misreporting. Curr Opin Clin Nutr Metab Care. (2002) 5:489-93. doi: 10.1097/00075197-200209000-00006

52. Hall JG, Pauli RM, Wilson KM. Maternal and fetal sequelae of anticoagulation during pregnancy. Am J Med. (1980) 68:122-40. doi: 10.1016/0002-9343(80)90181-3

53. Tamadon-Nejad S, Ouliass B, Rochford J, Ferland G. Vitamin K deficiency induced by warfarin is associated with cognitive and behavioral perturbations, and alterations in brain sphingolipids in rats. Front Aging Neurosci. (2018) 10:213. doi: 10.3389/fnagi.2018.00213

54. Sundaram KS, Lev M. Warfarin administration reduces synthesis of sulfatides and other sphingolipids in mouse brain. J Lipid Res. (1988) 29:1475-9.

55. Mongkhon P, Naser AY, Fanning L, Tse G, Lau WCY, Wong ICK, et al. Oral anticoagulants and risk of dementia: a systematic review and meta-analysis of observational studies and randomized controlled trials. Neurosci Biobehav Rev. (2019) 96:1-9. doi: 10.1016/j.neubiorev.2018.10.025 
56. Mostaza JM, Jiménez MJR, Laiglesia FJR, Peromingo JAD, Robles MB, Sierra EG, et al. Clinical characteristics and type of antithrombotic treatment in a Spanish cohort of elderly patients with atrial fibrillation according to dependency, frailty and cognitive impairment. J Geriatr Cardiol. (2018) 15:268-74. doi: 10.11909/j.issn.1671-5411.2018.04.004

57. Zhang C, Gu ZC, Shen L, Pan MM, Yan YD, Pu J, et al. Non-vitamin K antagonist oral anticoagulants and cognitive impairment in atrial fibrillation: insights from the meta-analysis of over 90,000 patients of randomized controlled trials and real-world studies. Front Aging Neurosci. (2018) 10:258. doi: 10.3389/fnagi.2018.00258

58. Shen L, Zhang C, Gu ZC, Lin HW, Liu XY, Pu J. Risk of cognitive impairment with non-vitamin $\mathrm{K}$ antagonist oral anticoagulants in atrial fibrillation: Protocol for a systemic review of randomized controlled trials and real-world studies. Medicine. (2018) 37:34. doi: 10.1097/MD.0000000000012072

59. Jacobs V, May HT, Bair TL, Crandall BG, Cutler MJ, Day JD, et al. Longterm population-based cerebral ischemic event and cognitive outcomes of direct oral anticoagulants compared with warfarin among long-term anticoagulated patients for atrial fibrillation. Am J Cardiol. (2016) 118:10-4. doi: 10.1016/j.amjcard.2016.04.039

60. Van den Heuvel EG, van Schoor NM, Vermeer C, Zwijsen RM, den Heijer M, Comijs HC. Vitamin K status is not associated with cognitive decline in middle aged adults. J Nutr Health Aging. (2015) 19:908-12. doi: 10.1007/s12603-015-0579-8

61. Sato Y, Honda Y, Hayashida N, Iwamoto J, Kanoko T, Satoh K. Vitamin K deficiency and osteopenia in elderly women with Alzheimer's disease. Arch Phys Med Rehabil. (2005) 86:576-81. doi: 10.1016/j.apmr.2004.10.005

62. Presse N, Shatenstein B, Kergoat MJ, Ferland G. Low vitamin K intakes in community-dwelling elders at an early stage of Alzheimer's disease. J Am Diet Assoc. (2008) 108:2095-9. doi: 10.1016/j.jada.2008.09.013

63. Presse N, Belleville S, Gaudreau P, Greenwood CE, Kergoat MJ, Morais JA, et al. Vitamin $\mathrm{K}$ status and cognitive function in healthy older adults. Neurobiol Aging. (2013) 34:2777-83. doi: 10.1016/j.neurobiolaging.2013.05.031

64. Chouet J, Ferland G, Féart C, Rolland Y, Presse N, Boucher K, et al. Dietary vitamin $\mathrm{K}$ intake is associated with cognition and behaviour among geriatric patients: the CLIP study. Nutrients. (2015) 7:6739-50. doi: 10.3390/nu7085306

65. Soutif-Veillon A, Ferland G, Rolland Y, Presse N, Boucher K, Féart C, et al. Increased dietary vitamin $\mathrm{K}$ intake is associated with less severe subjective memory complaint among older adults. Maturitas. (2016) 93:1316. doi: 10.1016/j.maturitas.2016.02.004

66. Kiely A, Ferland G, Ouliass B, O’Toole PW, Purtill H, O'Connor EM. Vitamin $\mathrm{K}$ status and inflammation are associated with cognition in older Irish adults. Nutr Neurosci. (2018) 2018:1-9. doi: 10.1080/1028415X.2018.1536411
67. Presse N, Gaudreau P, Greenwood CE, Kergoat MJ, Morais JA, Payette H, et al. A single measurement of serum phylloquinone is an adequate indicator of long-term phylloquinone exposure in healthy older adults. J Nutr. (2012) 142:1910-6. doi: 10.3945/jn.112.164608

68. Presse N, Shatenstein B, Kergoat MJ, Ferland G. Validation of a semiquantitative food frequency questionnaire measuring dietary vitamin $\mathrm{K}$ intake in elderly people. J Am Diet Assoc. (2009) 109:1251-5. doi: 10.1016/j.jada.2009.04.019

69. Annweiler C, Ferland G, Barberger-Gateau P, Brangier A, Rolland Y, Beauchet O. Vitamin $\mathrm{K}$ antagonists and cognitive impairment: results from a crosssectional pilot study among geriatric patients. J Gerontol A Biol Sci Med Sci. (2015) 70:97-101. doi: 10.1093/gerona/glu133

70. Ferland G, Feart C, Presse N, Lorrain S, Bazin F, Helmer C, et al. Vitamin K antagonists and cognitive function in older adults: the three-city cohort study. J Gerontol A Biol Sci Med Sci. (2016) 71:1356-62. doi: 10.1093/gerona/glv208

71. Brangier A, Celle S, Roche F, Beauchet O, Ferland G, Annweiler C. Use of vitamin $\mathrm{K}$ antagonists and brain morphological changes in older adults: an exposed/unexposed voxel-based morphometric study. Dement Geriatr Cogn Disord. (2018) 45:18-26. doi: 10.1159/000485793

72. Brangier A, Ferland G, Rolland Y, Gautier J, Féart C, Annweiler C. Vitamin $\mathrm{K}$ antagonists and cognitive decline in older adults: a 24-month follow-up. Nutrients. (2018) 10:6. doi: 10.3390/nu10060666

73. Cafolla A, Gentili A, Cafolla C, Perez V, Baldacci E, Pasqualetti D, et al. Plasma vitamin $\mathrm{K} 1$ levels in italian patients receiving oral anticoagulant therapy for mechanical heart prosthesis: a case-control study. Am J Cardiovasc Drugs. (2016) 16:267-74. doi: 10.1007/s40256-016-0169-0

74. Ansell J, Hirsh J, Hylek E, Jacobson A, Crowther MG, Palareti G. Pharmacology and management of the vitamin $\mathrm{K}$ antagonists: American College of Chest Physicians Evidence-Based Clinical Practice Guidelines (8th Edition). Chest. (2008) 133(6 Suppl):160S-98S. doi: 10.1378/chest.0 8-0670

Conflict of Interest Statement: The authors declare that the research was conducted in the absence of any commercial or financial relationships that could be construed as a potential conflict of interest.

Copyright (C) 2019 Alisi, Cao, De Angelis, Cafolla, Caramia, Cartocci, Librando and Fiorelli. This is an open-access article distributed under the terms of the Creative Commons Attribution License (CC BY). The use, distribution or reproduction in other forums is permitted, provided the original author(s) and the copyright owner(s) are credited and that the original publication in this journal is cited, in accordance with accepted academic practice. No use, distribution or reproduction is permitted which does not comply with these terms. 